\section{O debate sobre vacinas em redes sociais: uma análise exploratória dos links com maior engajamento}

\author{
The debate on vaccines in social networks: \\ an exploratory analysis of links with the heaviest \\ traffic
}
El debate sobre vacunas en redes sociales: un análisis exploratorio de los enlaces con mayor participación activa

Luisa Massarani 1,2

Tatiane Leal 1

Igor Waltz 1 doi: $10.1590 / 0102-311 \times 00148319$

\section{Resumo}

Esta pesquisa busca investigar o engajamento e as interações nas redes sociais sobre as vacinas. Com base na coleta dos 100 links mais compartilhados, curtidos e comentados entre maio de 2018 e maio de 2019, por meio da palavra-chave "vacina", foram identificadas os principais assuntos, fontes e posicionamentos. Em uma etapa qualitativa, foi empregado o método da Análise do Discurso para identificar os modos de produção de sentido em torno dos quais as conversações em rede se concentraram. Foi estudada ainda qual a participação das fake news entre os links mais compartilhados. Os resultados apontam que há majoritariamente uma disposição pró-vacina $(87,6 \%) e$ um forte interesse em temas ligados à saúde, ao desenvolvimento científico e às políticas de saúde. Por outro lado, parte das fontes de informação mais acessadas pelos brasileiros não traz informações sobre critérios editoriais, politicas ou autores, o que pode dificultar a apreensão da qualidade e veracidade das informações consumidas. Além disso, as fake news representaram 13,5\% dos links com maior engajamento, o que indica um dado preocupante em relação à desinformação sobre as vacinas. Esses resultados indicam importantes dinâmicas de comunicação sobre as vacinas e oportunidades para a melhoria na comunicação pública em torno do tema.

Vacinas; Rede Social; Comunicação e Divulgação Científica

\author{
L. Massarani \\ Instituto Nacional de Comunicação Pública da Ciência e \\ Tecnologia. \\ Av. Brasil 4036, Prédio da Expansão, sala 414, Rio de Janeiro, \\ RJ 21041-361, Brasil. \\ luisa.massarani6@gmail.com \\ 1 Instituto Nacional de Comunicação Pública da Ciência e \\ Tecnologia, Rio de Janeiro, Brasil. \\ 2 Casa de Oswaldo Cruz, Fundação Oswaldo Cruz, \\ Rio de Janeiro, Brasil.
}




\section{Introdução}

A vacinação em massa no mundo inteiro é uma contribuição fundamental da pesquisa científica no dia a dia das sociedades. Ela é um dos mais poderosos recursos para o exercício da saúde pública, atuante na erradicação e no controle de diversas doenças e na proteção de populações inteiras. Embora seus resultados tenham sido extremamente exitosos, estudos mostram que tem havido um aumento da desconfiança em torno da vacinação na última década, fazendo com que um crescente número de pessoas deixe de vacinar a si mesma e a seus filhos 1. Nos Estados Unidos, o percentual de pais que expressam algum tipo de preocupação em relação às vacinas aumentou de 19\% em 2000 para 50\% em 2009 2. Já entre os médicos, 89\% declararam, em uma survey de 2010, ter reportado ao menos um caso por mês de pais que se recusaram a vacinar seus filhos 3 .

Essa decisão não apresenta apenas um risco pessoal, gerando consequências em larga escala, já que possibilita o reaparecimento de doenças já controladas 4 . É o caso do sarampo, que tinha sido considerado controlado no ano 2000 nos Estados Unidos e em 2016 no Brasil. No entanto, a incidência da doença está crescendo exponencialmente em todo o mundo, em especial na Europa e nos Estados Unidos, o que levou o Fundo das Nações Unidas para a Infância (UNICEF) a lançar, em abril deste ano, a campanha \#VacinasFuncionam, alertando para o fato de que, a cada ano, mais de 20 milhões de crianças em todo o mundo deixam de receber a vacina contra o sarampo 5. Para a Organização Mundial da Saúde (OMS), a recusa da vacinação quando ela está disponível já consiste em uma das dez maiores ameaças à saúde no mundo 6 .

No contexto brasileiro, campanhas públicas têm encontrado dificuldade crescente em atingir metas de cobertura vacinal, como no caso do HPV em 20147 . Essa questão se agrava pela massiva proliferação de notícias falsas, como na epidemia de febre amarela, em 2017 e 2018 8. Nesse cenário, enfermidades já controladas têm retornado em níveis alarmantes, como o surto de sarampo em 2018 1,4. Ainda que possa haver múltiplos fatores determinantes para esses números, como a falta de acesso aos serviços de saúde e - também - o medo ou ceticismo em relação às vacinas 9 , é fundamental compreender o papel da informação sobre saúde nesse quadro, mais especificamente em uma mídia que vem adquirindo crescente relevância como meio de informações sobre ciência: a Internet.

Diante desse cenário, estudos têm apontado que a expansão do acesso às comunicações digitais transformou a Internet em uma das mais relevantes fontes de informação em saúde para a população ${ }^{10}$. Na ambiência digital, parte da autoridade de profissionais de saúde é paulatinamente transferida para os pacientes que assumem a responsabilidade de se informar por conta própria 11,12 . O "paciente-expert" seria mais do que meramente um cidadão bem informado, mas um consumidor especial de conteúdo de saúde, que se compreende como "entendido no assunto" e pode tornar-se resistente a orientações profissionais 13 . Contudo, o acesso ao grande volume de informações não necessariamente capacita os usuários a identificar a veracidade do que consomem. Estudos empíricos apontam que, paradoxalmente, usuários da Internet dizem atestar a credibilidade por meio das fontes dos sites e da linguagem científica, mas, na prática, a maioria se limita a abrir os primeiros resultados da busca, não procuram identificação dos autores e, raramente, recordam onde acessaram determinada informação 14 .

Não obstante o aumento do acesso à informação tenha trazido benefícios, também constitui um terreno fértil à dispersão de informações falsas e à tomada de posição radicalizada. Uma notícia falsa, ou fake news, pode ser entendida como um boato ou informação intencionalmente enganosa, com o propósito deliberado de gerar desinformação e prejudicar pessoas, grupos sociais, organizações ou mesmo países 15,16,17. Tais conteúdos não raramente apelam a manchetes, textos e imagens sensacionalistas, que retêm a atenção e se espalham rapidamente pela rede. Assim, a sobrecarga e a repetição de mensagens podem levar as pessoas a se "familiarizarem" com as informações falsas, dificultando a sua percepção e julgamento sobre a veracidade 18 .

De tal modo, as fake news consistem em um importante problema contemporâneo não apenas do ponto de vista social e político, mas também para a saúde pública. No caso das vacinas, ainda que a preocupação em torno da segurança remonte a outros contextos históricos, o advento das mídias sociais amplificou esse fenômeno, permitindo a disseminação do que a UNICEF chamou de uma "infecção real de desinformação" 19. A Internet se torna um campo privilegiado para a amplificação do discurso antivacina, caracterizado por uma série de objeções baseadas na suposta correlação entre 
preparações vacinais e males de causa pouco esclarecida; minimização da gravidade das doenças infecciosas; insinuações sobre a presença de compostos mercuriais; defesa das liberdades civis em vista do caráter compulsório da vacinação; e apelo à resistência contra as lucrativas corporações farmacêuticas 20 .

Em pesquisa feita em 140 países durante o ano de 2018, o Wellcome Global Monitor 1 investigou as opiniões e atitudes de mais de 140 mil pessoas diante da ciência e da saúde, oferecendo um panorama global sobre essas questões. A maior parte dos entrevistados concorda total ou parcialmente que as vacinas são eficazes (84\%) e seguras (79\%). No contexto da América do Sul, $82 \%$ concordam quanto à eficácia e $81 \%$ quanto à segurança. Ainda que os dados apontem para uma tendência positiva, a pesquisa também revelou que pessoas que recentemente buscaram informações sobre ciência (74\%) ou medicina e saúde (75\%) são menos propensas a concordar com a segurança das vacinas do que aquelas que não procuraram este tipo de informação ( $81 \%$ e $82 \%$, respectivamente). Esses resultados apontam a necessidade de pesquisas qualitativas para compreender que tipo de informação tem sido consumida sobre vacinação em diferentes contextos, e de que modo isto tem contribuído para formar a opinião pública acerca desse tema.

No Brasil, apesar do reconhecimento da importância das vacinas, a rápida disseminação de informações falsas indica um cenário de crescimento do discurso anticiência 8. Diante desse quadro, o trabalho almeja compreender que informações sobre vacinas foram mais consumidas e compartilhadas nas redes sociais no contexto brasileiro recente. Assim, analisamos as informações sobre vacina que mais circularam, no período pesquisado, em textos em língua portuguesa populares nas redes sociais, observando temáticas, enquadramentos e posicionamentos (pró ou contra as vacinas). Neste estudo, questionamos ainda quais os tipos de veículos on-line os brasileiros tomam como fontes de informação científica. Assim, partimos da hipótese de que o ambiente on-line propicia novos padrões de produção, consumo e distribuição de informações em saúde, nos quais os critérios de aferição da credibilidade ainda não foram plenamente esclarecidos ou consolidados. Diante desse "desordenamento informacional” 17, a Internet torna-se palco de tensões entre discursos pró e antivacina no contexto brasileiro.

\section{Métodos}

Esta pesquisa apresentou duas etapas metodológicas: a coleta do material empírico e a análise dos resultados. Na primeira fase, a investigação coletou por meio do BuzzSumo (https://buzzsumo.com/) os 100 links que alcançaram mais popularidade em redes sociais com base na palavra-chave "vacina". BuzzSumo é uma ferramenta de monitoramento digital para aferição de conteúdos mais compartilhados nas redes. Para fins de pesquisa, foi utilizada a versão gratuita para testes. A busca, realizada em 21 de maio de 2019, reuniu os links com maior engajamento - compartilhamentos, curtidas e comentários - no Facebook, Twitter, Pinterest e Reddit entre 22 de maio de 2018 e 21 de maio de 2019. Os dados foram exportados para uma planilha, a fim de preservá-los para análise após os sete dias gratuitos oferecidos pelo serviço. Ainda que a busca não tenha abrangido publicações em grupos fechados, nos quais conteúdos antivacina encontram forte respaldo 21, esse passo nos permite observar o quadro mais geral dos debates públicos nas redes sociais.

Entre os 100 links, 11 estavam fora do ar no momento da pesquisa, não sendo mais possível acessá-los. Portanto, a amostra válida consistiu em 89 links. Em meio à imensidão de dados potenciais que circulam no ambiente on-line 22,23, esse recorte possibilitou compreender que discursos sobre a vacinação foram mais compartilhados e comentados nesse período, despertando o interesse público e pautando a conversação sobre o tema nessas redes.

Na segunda fase, realizou-se uma análise do discurso dos dados reunidos pelo BuzzSumo. A análise do discurso é uma metodologia que rejeita a ideia de que a linguagem apenas descreve, de forma neutra, o mundo, tendo um papel central na construção da vida social 24 . Dentre as diversas correntes teóricas da análise do discurso, foi utilizada a perspectiva de Pinto 25, que compreende o discurso como uma prática social inserida em um contexto, com base no qual devem ser analisados criticamente os sentidos produzidos, de maneira a compreender disputas simbólicas, vieses ideológicos e relações de poder engendradas por estes conteúdos. Nesse sentido, mais do que verificar o que o texto diz, a análise do discurso se preocupa com de que maneira e por que ele diz, ou seja, seus modos de 
dizer. Em suma, analisar discursos que circulam em redes sociais baseando-se na análise do discurso permite refletir sobre o contexto sociohistórico em que são produzidos, veiculados e consumidos.

Foram seguidos os passos descritos por Gill 24 como característicos da análise do discurso: formulação das perguntas de pesquisa; seleção do córpus; leitura dos textos informada pela base teórica; codificação em categorias de análise; nova leitura e exame dos dados; e, por fim, a discussão dos resultados. Baseando-se nos objetivos dessa pesquisa, formulamos as seguintes categorias: (i) tema, observando quais doenças e enquadramentos mais apareceram entre esses discursos; (ii) posicionamento, analisando se eles são pró ou contra a vacinação; (iii) veracidade, utilizando procedimentos de fact checking para determinar se o texto traz informações comprovadas ou se trata de informação falsa; e (iv) tipo de veículo, de modo a identificar quem são os emissores e quais são os formatos dos textos mais compartilhados sobre a vacinação.

Nessa última categoria, elaboramos uma subdivisão entre veículos profissionais e não profissionais. Inspirados em pesquisas que determinaram critérios de avaliação da confiabilidade de fontes de informação em saúde 26,27, obedecemos aos seguintes fatores para avaliar um veículo como profissional: visão e política editorial bem definidas; indicação de endereço físico; identificação dos autores dos textos; e a citação de fontes para as informações. Os demais sites foram considerados não profissionais. Não se objetivou, assim, estabelecer uma dicotomia entre sites profissionais confiáveis e amadores não confiáveis, mas compreender um ecossistema midiático em que blogs e sites de variedades emergem como fontes primordiais em temas de ciência e saúde ao lado de mídias consolidadas ligadas a grandes empresas de comunicação.

\section{Resultados}

A amostra dos 89 links com mais engajamento fornece pistas para compreender como se dá a produção de sentido sobre as vacinas nos debates públicos das redes sociais. As categorias - tema, posicionamento, veracidade e tipo de veículo - foram estabelecidas para averiguarmos quais discursos circulam, as visões e os enunciadores predominantes e a confiabilidade das informações. Sobre os temas, há diferentes enquadramentos por meio dos quais a vacinação é abordada, com predomínio do campo da ciência e saúde (38 matérias, ou 42,7\% do total) e político (25, ou 28,1\%) (Figura 1).

\section{Figura 1}

Temas abordados nos textos que geraram maior engajamento em redes sociais, entre maio de 2018 e maio de 2019 , contendo a palavra-chave "vacina".

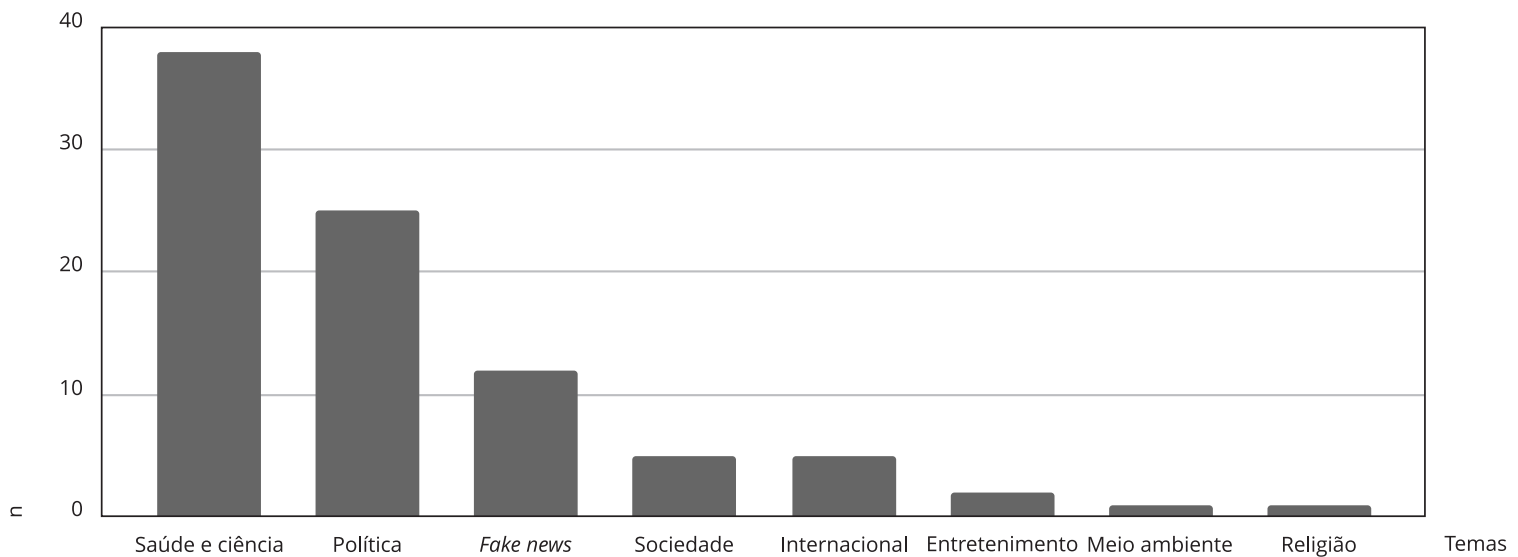


A área de saúde e ciência foi a que despertou o maior interesse por parte dos usuários, com o maior volume de links comentados, curtidos e compartilhados. A maioria dessas matérias versou sobre pesquisas para novas vacinas, novas aplicações para vacinas já conhecidas e a segurança destas preparações. Há também, em menor quantidade, dicas e informações para o cuidado com a própria saúde, como a importância da vacina contra herpes-zóster após os 50 anos e os cuidados da família antes da chegada de um novo bebê.

O campo da política também apresentou grande abrangência. Nesse escopo, incluíram-se discussões sobre promoção e ampliação da cobertura vacinal e as preocupações em torno das metas de vacinação. No período, também houve uma grande concentração em torno do personagem do ex-presidente Luiz Inácio Lula da Silva, que perdeu seu neto em março de 2019 com suspeita de meningite. Um grande volume de matérias verdadeiras e de fake news abordou o assunto, discutindo medidas tomadas durante a gestão do ex-presidente a respeito do conjunto de vacinas disponíveis no Sistema Único de Saúde (SUS).

Também houve matérias sobre temas cotidianos, classificados como "sociedade", tais como o roubo de um caminhão com lotes de vacinas no Rio de Janeiro e a vacinação de pessoas em regime prisional. Assuntos como a lei italiana para afastar crianças sem vacina das escolas, a crise humanitária da República Democrática do Congo e o crescimento de casos de sarampo e poliomielite em todo o mundo foram catalogadas como "internacional".

Salienta-se que essa divisão por temáticas foi feita de modo arbitrário, a fim de se perceber qual o campo predominante em cada texto. Assim, matérias como Politico Antivacina é Internado com Catapora, da revista Claudia, apesar de ter interfaces com a discussão política e saúde, é aqui classificada como internacional, uma vez que se trata dos desdobramentos do movimento antivacina em outro país.

As fake news responderam por $13,5 \%$ do total de links com maior engajamento. O peso das notícias falsas no cenário analisado é evidenciado também pela quantidade de conteúdos produzidos com base em fact checking. Ao todo foram sete matérias (7,86\%) desmentindo informações falsas, sendo três de meios jornalísticos (Zero Hora, UOL e Último Segundo), dois de sites especializados na prática (E-farsas e Boatos.org), um institucional (da Associação Brasileira de Saúde Coletiva - Abrasco) e um site de comentários políticos (Plantão Brasil). Isso demonstra que a preocupação com a veracidade e a correção de informações também é um fator de engajamento nas redes sociais.

Além disso, no período analisado, observou-se a primazia de matérias que versavam sobre meningite, em grande parte impulsionadas pela morte do neto do ex-presidente Lula. Ao todo, foram 18 links discutindo o tema, das ações governamentais à procura pela vacina em postos e clínicas. Também houve forte interesse por doenças como leishmaniose animal (sete links), HIV/aids (sete), câncer (cinco), febre amarela (quatro), alergias (quatro) e vício em drogas (quatro). Além disso, oito links apontaram para discussões que não envolveram uma doença específica, como a situação de filhos de mulheres encarceradas ou pesquisas que descartaram a relação entre vacinas e autismo (Figura 2).

A soma total das doenças abordadas é maior do que o número de links porque alguns deles versaram sobre mais de uma enfermidade, como no caso do estudo brasileiro que afirma que a vacina da febre amarela pode proteger contra Zika, noticiado pela BBC Brasil. Além disso, houve um grande espaço para as chamadas "vacinas terapêuticas", isto é, preparações destinadas a pessoas já portadoras de determinada doença para melhorar sua resposta imunológica. Ao todo foram 21 links abordando a questão de vacinas para a terapia de doenças como HIV/aids, diabetes, câncer e rinites alérgicas. Já entre as 12 fake news identificadas, sete delas geraram desinformação sobre as vacinas da gripe (58,3\%), duas sobre meningite (16,7\%), duas sobre câncer (16,7\%) e uma sobre febre amarela $(8,3 \%)$.

Em relação ao posicionamento, 78 textos foram classificados como pró-vacina $(87,6 \%)$ e 8 como contra (9\%). Três deles foram classificados como metáfora $(3,4 \%)$ por se referirem à vacina de forma figurada (Figura 3).

Em relação à veracidade, 72 textos foram classificados como informações verdadeiras $(80,9 \%)$ e 12 como fake news (13,5\%). Em cinco dos links essa divisão não se aplica: os três casos de metáfora (3,4\%) e dois conteúdos enquadrados como entretenimento (2,2\%): a cena de uma novela da Rede Globo e um vídeo humorístico do Porta dos Fundos no YouTube (Figura 4).

Já os tipos de veículo foram categorizados entre sites profissionais e não profissionais. Essa categorização permite identificar quais são as principais fontes de informação dos usuários no contexto do debate sobre vacinas. Como já dito anteriormente, veículos profissionais são compreendidos por 


\section{Figura 2}

Doenças mais abordadas nos textos que geraram maior engajamento em redes sociais, entre maio de 2018 e maio de 2019 , contendo a palavra-chave "vacina".

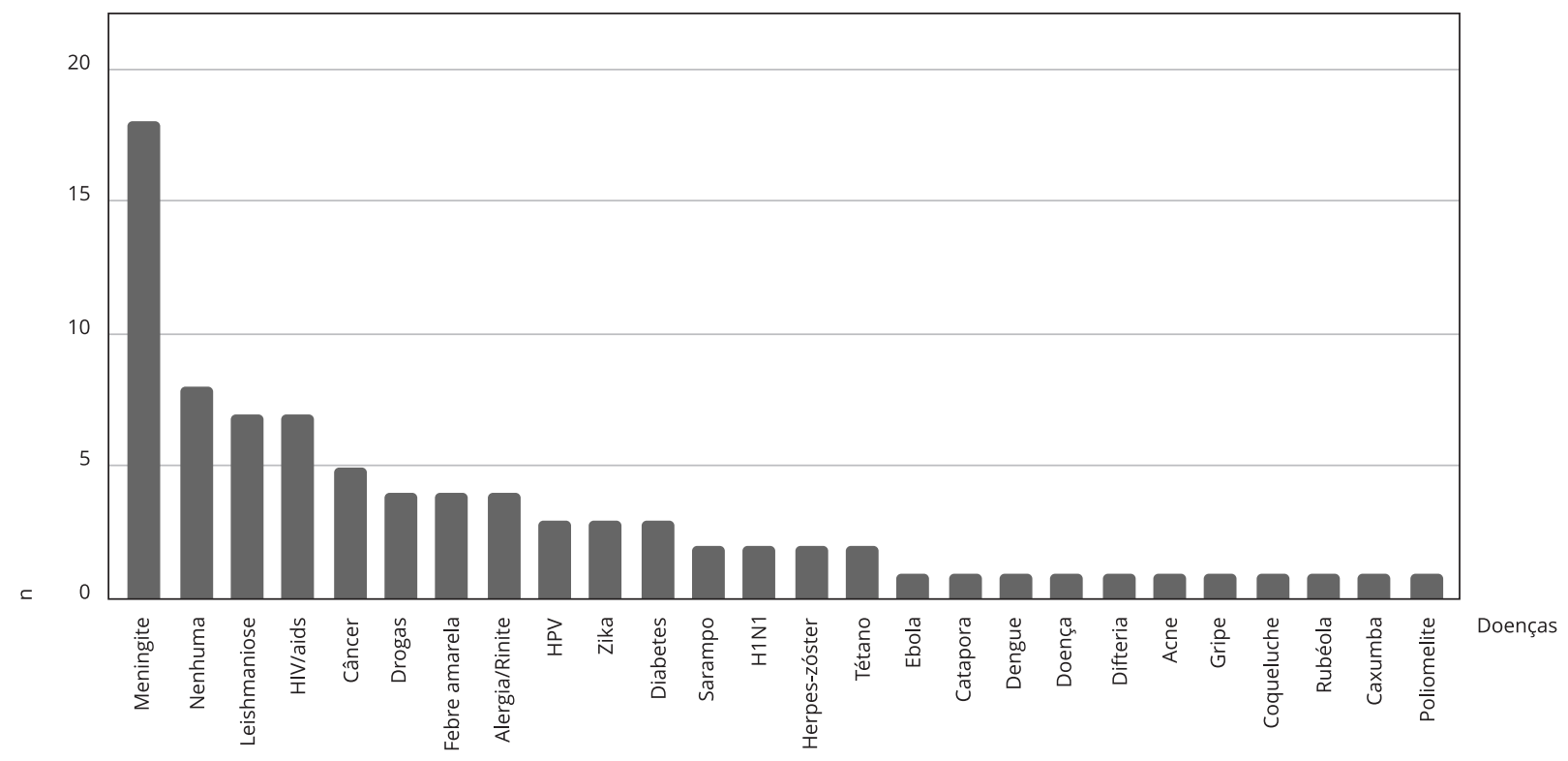




\section{Figura 3}

Posicionamento em relação à vacinação presente nos textos que geraram maior engajamento em redes sociais, entre maio de 2018 e maio de 2019 , contendo a palavra-chave "vacina".

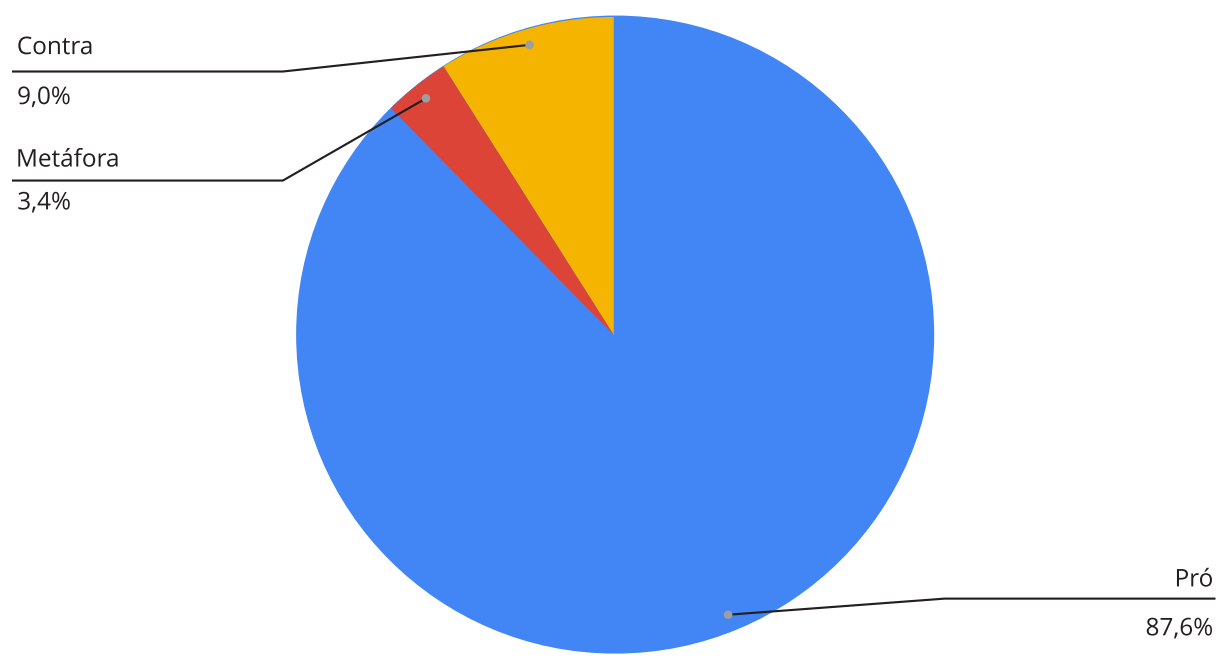

\section{Figura 4}

Avaliação da veracidade do conteúdo dos textos que geraram maior engajamento em redes sociais, entre maio de 2018 e maio de 2019, contendo a palavra-chave "vacina".

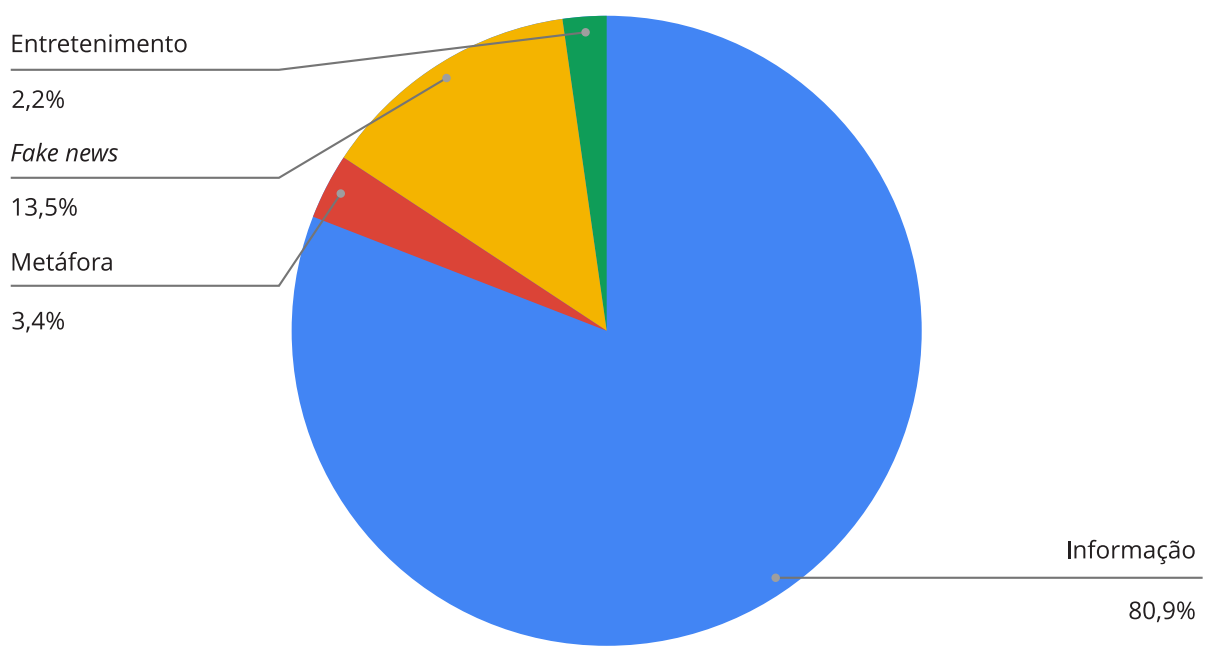


Categorização dos tipos de veículos profissionais encontrados entre os emissores dos textos que geraram maior engajamento em redes sociais, entre maio de 2018 e maio de 2019, contendo a palavra-chave "vacina".

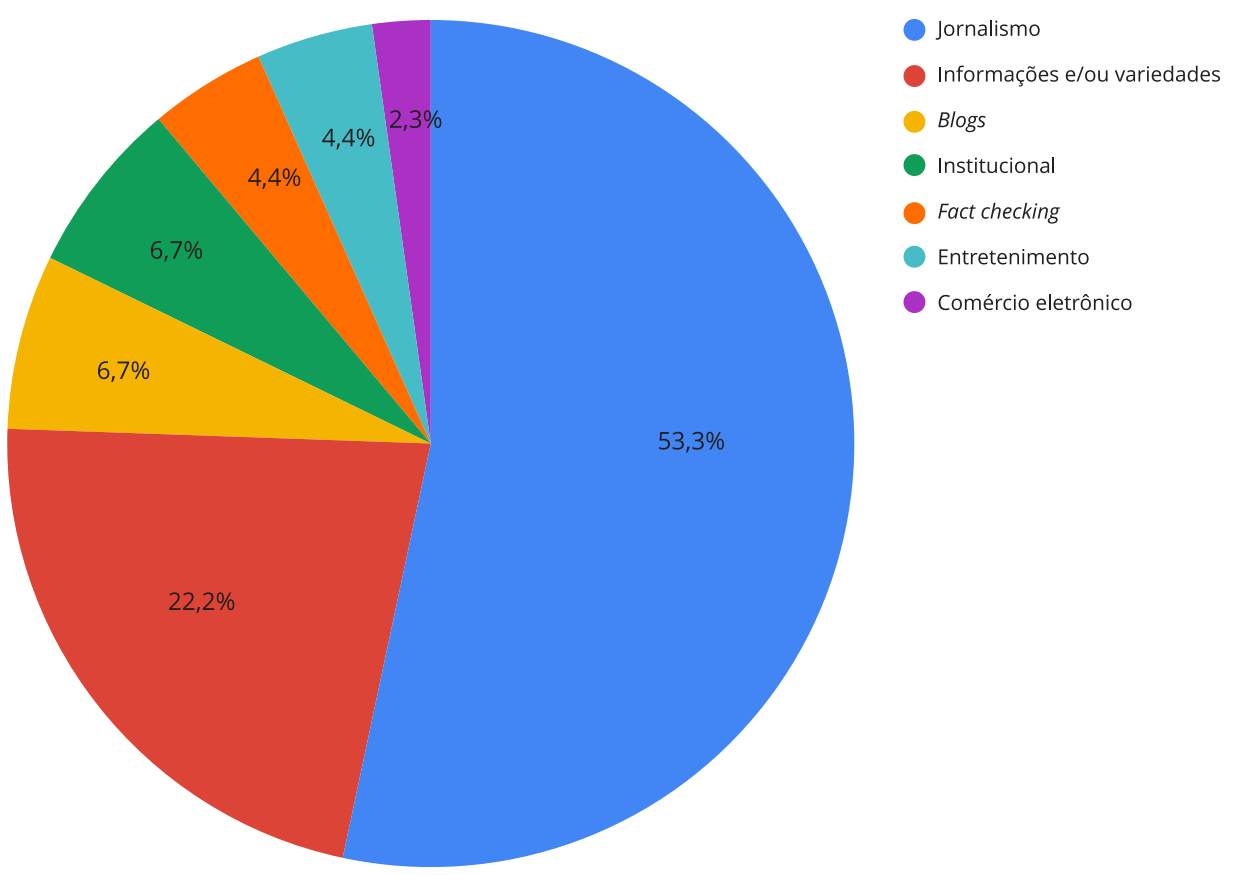

se trata de estabelecer um juízo de valor, mas identificar seus modos de atuação e presença nas redes. Sem informações sobre os critérios que norteiam a veiculação, torna-se difícil atestar a qualidade e a precisão dos conteúdos. Entre essas páginas, nove propagaram fake news sobre vacinas.

\section{Discussão}

A análise dos dados coletados aponta importantes tendências, dinâmicas e contradições a respeito dos debates públicos sobre vacina nas redes sociais. Assuntos ligados à pesquisa científica em saúde tiveram grande peso no engajamento dos usuários. Contudo, a maior parte das interações em torno desse tópico aconteceu primariamente com base em veículos jornalísticos e sites de variedades, com participação pequena de instituições acadêmico-científicas. Além disso, não estiveram presentes entre os links de maior engajamento páginas de órgãos governamentais ligados às áreas da saúde e C\&T, tais como ministérios, agências reguladoras, secretarias municipais e estaduais, entidades de fomento à pesquisa etc. Ou seja, é possível concluir que há um interesse social sobre vacinas novas e em desenvolvimento, mas que a comunicação produzida pelas instituições acadêmico-científicas tem uma participação limitada em pautar estas conversações.

Além disso, há um forte interesse sobre a questão das "vacinas terapêuticas". Nesse sentido, doenças como HIV/aids, câncer e diabetes suscitaram mais engajamento no período do que doenças que podem ser prevenidas pelas vacinas e que, inclusive, vêm passando por um crescimento do número de casos, como o sarampo. E mais, o caso envolvendo a família de uma proeminente figura pública - o ex-presidente Lula - ajudou a alavancar o debate em torno de um tema específico - a meningite.

A significativa predominância do posicionamento favorável à vacina demonstra que os discursos que partem do princípio de que a vacinação é segura, eficaz e necessária geraram mais engajamento do 
que os de visão contrária. Nesses textos, a vacina é associada ao progresso da ciência e aos benefícios que trazem à população. A presença da categoria metáfora, ainda que em um percentual pequeno, demonstra que a palavra vacina é utilizada como sinônimo para prevenção e combate, o que indica um conhecimento básico disseminado sobre as funções dessa tecnologia e sua incorporação no imaginário social.

Mesmo em menor número, oito textos de posicionamento contrário à vacina figuram entre os 100 links mais populares em redes sociais, portanto, é importante compreender de que forma a vacinação é abordada nesses discursos. Sete deles são fake news, confirmando que é no terreno das informações falsas que o discurso antivacina se prolifera predominantemente. Seis delas referem-se ao caso de uma adolescente de 14 anos que teria engravidado após tomar a vacina da gripe em uma clínica nos Estados Unidos. Esse caso aparece em metade dos links classificados como fake news. Os textos repetem, essencialmente, as mesmas informações: uma jovem em perfeito estado de saúde apresenta fortes sintomas de febre e náusea depois da imunização e, após exames, é atestada a gravidez. Ela declara nunca ter tido relações sexuais e a condição é verificada por um médico, que confirma a vacina como a causa da gestação.

Três dos seis textos trazem ainda uma seção discutindo a "gravidez vacinal", apresentando supostas fontes científicas, casos semelhantes e estatísticas. As informações são referendadas por uma suposta cientista e pela Organização das Nações Unidas (ONU), que teria apurado que 4 mil pessoas engravidam por ano em decorrência de vacinação. Por último, é citado um caso de 2013, no México, em que 11 meninas teriam engravidado devido a um lote contaminado da vacina contra o HPV, fato alegadamente confirmado pelas autoridades de saúde mexicanas.

Como postula a análise do discurso, a escolha das palavras e das estratégias de enunciação não é aleatória, mas responde ao contexto social em que o texto foi produzido e às intenções ideológicas que atravessam este cenário. Inicialmente, reforça-se a ideia de uma pessoa em perfeito estado de saúde que sai da vacinação com sintomas de doença. Em seguida, não são quaisquer indivíduos, mas meninas, crianças e adolescentes que deveriam ser protegidas pelas autoridades de saúde, mas foram expostas a lotes contaminados. Por fim, há um apelo à comunidade científica para que pare de evitar esse assunto controverso, de forma a impedir que essa situação trágica se repita.

O texto reforça uma visão contrária à vacinação, disseminando temores comuns entre a parcela da população que duvida parcial ou totalmente da segurança e da eficácia das vacinas: os efeitos colaterais, a negligência das autoridades, a parcialidade dos cientistas; elementos que, combinados, colocariam em risco pessoas saudáveis, especialmente crianças. No contexto da vacinação contra o HPV no Brasil, por exemplo, a vacina foi vista pelos grupos contrários como uma imposição irresponsável das autoridades sobre suas filhas, expondo-as a perigosos efeitos colaterais escondidos pelos cientistas e a um incentivo precoce à sexualidade 7 . Não por acaso estão presentes no texto da notícia falsa a vacina do HPV e a gravidez de uma menina virgem, efeito extremo sofrido por uma adolescente indefesa, decorrente de uma tentativa não segura de prevenir uma doença simples, a gripe.

Dentre as sete fake news de posicionamento contrário à vacina, há outro texto que se refere à imunização contra gripe. Segundo ele, o presidente norte-americano Donald Trump teria afirmado que "a vacina da gripe é a maior fraude da história da medicina", arquitetada pela indústria farmacêutica para ganhar dinheiro. Mais uma vez, há o reforço da vacina como um mal que pode adoecer pessoas saudáveis, indefesas diante das autoridades e dos cientistas que atuariam em benefício próprio, produzindo também uma visão da ciência como parcial e perigosa. Portanto, ainda que em menor número dentre os textos analisados, não se pode negligenciar os possíveis efeitos da reverberação de discursos antivacina no ambiente on-line e sua influência na promoção de atitudes anticiência.

A notícia verdadeira que passa uma visão contrária à vacinação é Menino que Morreu Após Tomar Vacina contra o Tétano Avisou a Mãe que Estava Passando Mal, do site informativo Mãe Tips. As estratégias de enunciação levantam dúvidas sobre a segurança das vacinas e a confiabilidade de cientistas e agentes de saúde. Segundo o texto, no caso ocorrido em uma clínica particular no Paraná, um menino de 12 anos teria se sentido mal e o médico teria afirmado que os sintomas seriam uma reação à vacina. A mãe relata que o menino começou a sufocar e a espumar pela boca, reações severas e imediatas à injeção. A matéria afirma que o caso está sob investigação e traz uma nota da Secretaria de Estado da Saúde, que acredita em uma troca de medicamentos como motivo do óbito. 
Ainda que a matéria não afirme categoricamente que a vacina seria a causa da morte, esta interpretação pode ocorrer, especialmente, pelo título. Em um cenário contemporâneo em que a atenção dos usuários é disputada por um enorme volume de informações nas redes sociais, é comum a recirculação das informações sem o seu pleno consumo. Ou seja, muitas vezes, o conteúdo é compartilhado apenas com a leitura da chamada que aparece na interface do Twitter e do Facebook, sem que o link seja sequer acessado, especialmente quando o título confirma crenças e opiniões prévias. Essa prática pode gerar uma compreensão parcial ou equivocada das informações que circulam na rede 31 .

Entre as 12 fake news encontradas, cinco têm posicionamento favorável em relação às vacinas. Alguns de seus elementos discursivos diagnosticam problemas na relação entre sociedade, ciência e saúde pública. Uma delas é Cuba Produz Vacina Contra o Câncer - Mais de 4 Mil Pessoas já Foram Curadas por Ela!, do blog Papo Reto. Ainda que o texto traga informações verdadeiras sobre o desenvolvimento de imunoterapia contra o câncer de pulmão, o título afirma categoricamente a cura da doença pela vacina. No corpo do texto, explica-se que, na verdade, o medicamento possibilitou a melhora de sintomas e o prolongamento do tempo de vida dos pacientes. Portanto, consideramos uma fake news, por tratar de uma manchete sensacionalista que induz a um falso sentido, com fins políticos: a matéria elogia Cuba como representante de uma "ciência do bem".

A escolha dessa expressão remete ao seu oposto, os "gigantes farmacêuticos". Mais uma vez, há a produção da ideia de uma ciência do mal, que poderia curar populações, mas não o faz por ser orientada por interesses financeiros. Assim, ainda que a vacina seja vista como positiva, os processos de produção e distribuição desta tecnologia, representados pela indústria farmacêutica, agentes de saúde, governos e cientistas mal-intencionados são vistos como negativos. Esse discurso pode significar um entrave à adesão da população a campanhas de vacinação, necessariamente mediadas por esses agentes.

Outras duas fake news de visão positiva estão relacionadas a políticas públicas de vacinação. $\mathrm{O}$ título das matérias é o mesmo: SUS Passa a Oferecer Vacina para Crianças Contra Meningite. Entretanto, o que ocorreu foi uma ampliação da cobertura, que já atendia à população infantil até os cinco anos, para crianças acima desta idade com fatores de risco. O subtítulo Portaria foi Divulgada no Diário Oficial da União desta Quarta-feira (6); Neto do Ex-presidente Lula Morreu na Última Sexta (1ọ) Vítima da Doença" associa o acontecimento a fins políticos, produzindo um sentido que, mais uma vez, pode levar a atitudes de desconfiança em relação aos atores envolvidos no processo de produção e distribuição das vacinas.

Essa questão também aparece na fake news Lula Vetou em 2010 Vacina para Meningite, Doença que Matou seu Neto de 7 Anos. Na análise do discurso, os enunciados não devem ser compreendidos isoladamente, mas em relação dentro de um campo discursivo 25. Circulando na mesma época, essas fake news constroem um cenário social em que a vacinação é uma prática regida por autoridades não confiáveis, que teriam submetido milhares de crianças a uma doença evitável, cenário que só teria mudado depois que o ente de uma delas foi atingido. Além de a meningite não ter sido a causa da morte - o neto do ex-presidente faleceu em março de 2019 devido à sepse originada pela bactéria Staphylococcus aureus -, Lula apenas vetou um Projeto de Lei que previa a inclusão da vacina contra a meningite meningocócica $C$ (conjugada), uma vez que ela já estava contemplada no calendário básico de vacinação.

Além disso, a popularidade desses discursos indica um desconhecimento da população quanto à cesta de vacinas oferecidas pelo SUS. Não saber que vacinas podem ser obtidas gratuitamente e desconfiar do processo de vacinação pública podem afastar parte da população desta prática, impedindo-a de reconhecer a imunização como um direito que deve ser garantido.

Outra notícia falsa analisada, a única publicada em um site profissional (Paraná Portal), refere-se a uma vítima da febre amarela que teria assinado um termo se recusando a tomar a vacina contra a doença. A informação, presente no título, aparece no corpo do texto em uma entrevista do diretor da 1a Regional de Saúde de Paranaguá. Em contato com o órgão, confirmamos que a informação é falsa. O caso é usado na reportagem para reforçar a importância da vacinação em um contexto de epidemia da doença. Não é possível afirmar, entretanto, se houve erro de apuração ou produção deliberada de notícia falsa.

Por fim, ao discutir conjuntamente os resultados acerca do posicionamento e da veracidade dos links analisados, é necessária uma reflexão sobre a presença de fake news e de discursos contra a vacina 
entre os links mais compartilhados entre 2018 e 2019. Por um lado, o predomínio de informações verdadeiras e de discursos pró-vacina reforça que a vacinação ainda é predominantemente vista como benéfica e necessária, e que as redes sociais são um espaço importante na contemporaneidade para a busca de informações científicas, cujo potencial deve ser explorado para promover a participação e o acesso ao conhecimento científico.

Por outro lado, o menor volume dos discursos contra a vacinação entre os links de maior engajamento, em um contexto de crescimento do discurso antivacina, não representa uma contradição, e sim demonstra a necessidade de pensar hipóteses que direcionam novos esforços de pesquisa. Uma delas é a de que esse movimento não atua prioritariamente nos espaços públicos do Facebook e do Twitter, mas em outras ambiências midiáticas, como grupos fechados no Facebook e no Whatsapp. Nesses espaços privados, os critérios de veracidade seriam ditados pelas dinâmicas do próprio grupo, que se afastaria de fontes tradicionais de informação, como veículos midiáticos, instituições acadêmicas, científicas e políticas e se apoiaria na própria comunidade como espaço de mediação do real.

E mais, mesmo nos espaços analisados pelo BuzzSumo, deve-se considerar o papel das câmaras de eco ou bolhas de filtro, que surgem quando os algoritmos aplicados ao conteúdo on-line medem seletivamente o que o usuário deseja ver com base em seu perfil, conexões e histórico de navegação. A repetição das mesmas informações impede a exposição desses usuários a outros posicionamentos, promovendo visões polarizadas e critérios de veracidade restritos a esses espaços 15. É preciso pensar em alternativas para romper essas bolhas, promovendo um acesso amplo da população a informações científicas de qualidade.

\section{Considerações finais}

A realização deste estudo possibilitou a identificação das dinâmicas de engajamento em torno do debate sobre vacinas nas redes sociais. Verificou-se que predomina um posicionamento positivo a respeito das vacinas, mesmo em um contexto de crescimento de discursos antivacinação. Observouse ainda o expressivo interesse dos usuários em temas ligados à pesquisa científica, ainda que as principais fontes para tais informações não sejam entidades da área de P\&D. Além disso, a presença de fake news deve servir de alerta para o papel da desinformação nas redes sociais. Elas assinalam tanto para um descrédito da segurança sobre as vacinas quanto para uma associação a determinados vieses políticos. Por outro lado, a presença também de matérias resultantes de fact checking entre as de maior engajamento pode evidenciar que a preocupação com a veracidade é presente nas conversações em redes digitais. Por fim, a pesquisa pretende contribuir para o desenvolvimento e aperfeiçoamento de estratégias de comunicação para o acesso e a qualidade do debate sobre a segurança e a eficiência das vacinas. 


\section{Colaboradores}

L. Massarani foi responsável por fazer a proposta geral do estudo sobre vacinas e redes sociais, participou do desenho metodológico deste trabalho em particular, bem como supervisionou e orientou o estudo e a redação do texto do artigo. T. Leal participou do desenho metodológico deste estudo em particular, foi responsável pela coleta dos dados, análise e interpretação do material e redação do manuscrito. I. Waltz contribuiu com a análise e interpretação dos dados e com a redação do texto.

\section{Informações adicionais}

ORCID: Luisa Massarani (0000-0002-5710-7242); Tatiane Leal (0000-0002-0410-809X); Igor Waltz (0000-0003-1903-6153).

\section{Agradecimentos}

Os autores agradecem o apoio concedido ao Instituto Nacional de Comunicação Pública da Ciência e Tecnologia pelo Conselho Nacional de Desenvolvimento Científico e Tecnológico (CNPq; processo no 465658/2014-8) e pela Fundação Carlos Chagas Filho de Amparo à Pesquisa do Estado do Rio de Janeiro (FAPERJ; processo no E-26/010.000078/2018), nos quais está contemplada a bolsa de pós-doutoramento de T. Leal (FAPERJ; processo no E-26/200.180/2019) e DTI de. I. Waltz (CNPq; processo no 370021/2020-7).

\section{Referências}

1. Wellcome Global Monitor. How does the world feel about science and health? https:// wellcome.ac.uk/what-we-do/our-work/ wellcome-global-monitor (acessado em 19/ Jun/2019).

2. Gowda C, Dempsey AF. The rise (and fall?) of parental vaccine hesitancy. Hum Vaccin Immunother 2013; 9:1755-62.

3. Kempe A, Daley MF, McCauley MM, Crane LA, Suh CA, Kennedy AM, et al. Prevalence of parental concerns about childhood vaccines: the experience of primary care physicians. Am J Prev Med 2011; 40:548-55.

4. Hortal M, Di Fabio JL. Rechazo y gestión en vacunaciones: sus claroscuros. Rev Panam Salud Pública 2019; 43:e54.

5. Fundo das Nações Unidas para a Infância. A cada ano, mais de 20 milhões de crianças em todo o mundo não recebem a vacina contra o sarampo. https://www.unicef.org/brazil/ comunicados-de-imprensa/cada-ano-maisde-20-milhoes-de-criancas-em-todo-o-mun do-nao-recebem-vacinas (acessado em 25/ Abr/2019).

6. World Health Organization. Ten threats to global health in 2019. https://www.who.int/ emergencies/ten-threats-to-global-health -in-2019 (acessado em 25/Abr/2019).

7. Quevedo JP, Inácio M, Wieczorkievicz AM, Invernizzi $\mathrm{N}$. A política de vacinação contra o HPV no Brasil: a comunicação pública oficial e midiática face à emergência de controvérsias. Revista Tecnologia e Sociedade 2016; 12:1-26.

8. Sacramento I. A saúde numa sociedade de verdades. RECIIS (Online) 2018; 12:4-8.

9. Massarani L, Araripe C. Aumentar o diálogo com a sociedade é uma questão de sobrevivência para a Ciência brasileira. Cad Saúde Pública 2019; 35:e00089619.

10. Moretti FA, Oliveira VE, Silva EMK. Acesso a informações de saúde na internet: uma questão de saúde pública? Rev Assoc Méd Bras 2012; 58:650-8.

11. Katta A. A postmodern Pandora's Box: antivaccination misinformation on the Internet. Vaccine 2010; 28:1709-16.

12. Katta A. Anti-vaccine activists, Web 2.0, and the postmodern paradigm: an overview of tactics and tropes used online by the anti-vaccination movement. Vaccine 2012; 30:3778-89.

13. Garbin HBR, Pereira Neto AF, Guilam MCR. A internet, o paciente expert e a prática médica: uma análise bibliográfica. Interface Comun Saúde Educ 2008; 12:579-88.

14. Eysenbach G, Köhler C. How do consumers search for and appraise health information on the world wide web? Qualitative study using focus groups, usability tests, and in-depth interviews. BMJ 2002; 324:573-7.

15. Bakir V, McStay A. Fake news and the economy of emotions: problems, causes, solutions. Digital Journalism 2017; 6:154-75. 
16. Recuero R, Gruzd A. Cascatas de fake news políticas: um estudo de caso no Twitter. Galáxia 2019; 41:31-47.

17. Wardle C, Derakhshan H. Information disorder: toward an interdisciplinary framework for research and policymaking. Strasbourg: Council of Europe; 2017.

18. Paul C, Matthews M. The Russian "firehose of falsehood" propaganda model: why it might work and options to counter it. Perspectives 2016; PE-198-OSD.

19. United Nations Children's Fund. Alarming global surge of measles cases a growing threat to children. https://www.unicef.org/press-re leases/alarming-global-surge-measles-casesgrowing-threat-children-unicef-0 (acessado em 28/Fev/2019).

20. Vasconcellos-Silva PR, Castiel LD. A internet na história dos movimentos anti-vacinação. ComCiência 2010; (121):1-4.

21. Smith N, Grahan T. Mapping the anti-vaccination movement on Facebook. Information, Communication \& Society 2019; 22:1310-27.

22. Fragoso S, Recuero R, Amaral A. Métodos de pesquisa para internet. Porto Alegre: Sulina; 2016.

23. Hine C. Estratégias para etnografia da internet em estudos de mídia. In: Campanella B, Barros $\mathrm{C}$, organizadores. Etnografia e consumo midiático: novas tendências e desafios metodológicos. Rio de Janeiro: E-papers; 2016. p. 11-27.

24. Gill R. Análise do discurso. In: Bauer MW, Gaskell G, organizadores. Pesquisa qualitativa com texto, imagem e som: um manual prático. Petrópolis: Editora Vozes; 2002. p. 244-70.
25. Pinto MJ. Comunicação e discurso: introdução à análise do discurso. São Paulo: Hacker; 1999.

26. Mendonça APB, Pereira Neto A. Critérios de avaliação da qualidade da informação em sites de saúde: uma proposta. RECIIS (Online) 2015; 9:1-15.

27. Silva LM, Luce B, Silva Filho RC. Avaliação de critérios para fontes de informações na área da saúde no contexto da pós-verdade. In: Anais do IV Encontro Regional dos Estudantes de Biblioteconomia, Documentação, Ciência e Gestão da Informação. Porto Alegre: Universidade Federal do Rio Grande do Sul; 2017. https://lume.ufrgs.br/bitstream/hand le/10183/157720/001021282.pdf.

28. Silva G, Silva MP, Fernandes ML, organizadores. Critérios de noticiabilidade: problemas conceituais e aplicações. Florianópolis: Insular; 2014.

29. Traquina N. Teorias do jornalismo: porque as notícias são como são. v. 1. 3a Ed. Florianópolis: Insular; 2012.

30. Wolf M. Teorias da comunicação. 5a Ed. Lisboa: Presença; 1999.

31. Zago GS, Silva ALM. Sites de rede social e economia da atenção: circulação e consumo de informações no Facebook e no Twitter. Vozes e Diálogo 2014; 13:5-17. 


\section{Abstract}

This study aims to analyze Internet traffic and interactions on social networks concerning vaccines. The 100 most widely shared, liked, and commented links were visited with the keyword "vaccine" from May 2018 to May 2019 to identify the main subjects, sources, and positions. The qualitative study phase used Discourse Analysis to identify modes of production of principal meanings in the chats. We further studied the fake news in the most widely shared links. The results point to a majority position in favor of vaccines (87.6\%) and strong interest in health-related themes, scientific development, and health policies. Meanwhile, some of the mostly widely accessed sources of information in Brazil had no information on editorial criteria, policies, or authors, making it difficult to determine the quality and veracity of the information consumed in social networks in Brazil. Fake news accounted for $13.5 \%$ of the links with the heaviest traffic, raising concerns about misinformation on vaccines. These results point to important communication dynamics related to vaccines and opportunities to improve public communication on vaccination.

Vaccines; Social Networking; Scientific Communication and Diffusion

\section{Resumen}

El objetivo de esta investigación es investigar la participación activa y las interacciones en las redes sociales sobre las vacunas. En base a la recogida de los 100 enlaces más compartidos, con "me gusta", y comentados entre mayo de 2018 y mayo de 2019, mediante la palabra-clave "vacuna", fueron identificados los principales asuntos, fuentes $y$ posicionamientos. En una etapa cualitativa, se empleó el método del Análisis del Discurso para identificar los modos de producción de sentido, alrededor de los que se concentraron las conversaciones en red. Asimismo, se estudió cuál es la participación de las fake news entre los enlaces más compartidos. Los resultados apuntan que existe mayoritariamente una disposición pro-vacuna (87,6\%) y un fuerte interés en temas relacionados con la salud, con el desarrollo científico y las politicas de salud. Por otro lado, parte de las fuentes de información más consultadas por los brasileños no proporcionaron información sobre criterios editoriales, políticas o autores, lo que puede dificultar la aprehensión de la calidad y veracidad de la información consumida. Asimismo, las fake news representaron un 13,5\% de los enlaces con mayor participación, lo que indica un dato preocupante respecto a la desinformación sobre las vacunas. Estos resultados indican importantes dinámicas de comunicación sobre las vacunas y oportunidades para una mejora en la comunicación pública en torno a este tema.

Vacunas; Red Social; Comunicación y Divulgación Científica
Recebido em 12/Ago/2019

Versão final reapresentada em 08/Out/2019 Aprovado em 30/Out/2019 